\title{
Cross-pathway Regulation of Ornithine Carbamoyltransferase Synthesis in Aspergillus nidulans
}

\author{
By M. PIOTROWSKA \\ Institute of Biochemistry and Biophysics, Polish Academy of Sciences, \\ Rakowiecka 36, 02-532 Warsaw, Poland
}

(Received 14 February 1979)

\begin{abstract}
Regulation of the cross-pathway type was found in Aspergillus nidulans. Ornithine carbamoyltransferase, a biosynthetic enzyme of the arginine pathway, is derepressed as a result of deprivation not only of arginine but also of histidine, proline and tryptophan. Crosspathway regulation operates in the mutant $s u D 19$ in which the ornithine carbamoyltransferase level is insensitive to arginine. The spectrum of the amino acids involved in this type of regulation seems to be different from those described for other fungi.
\end{abstract}

\section{INTRODUCTION}

The phenomenon of general or cross-pathway regulation of the biosynthesis of amino acids has been described for the fungus Neurospora crassa (Carsiotis et al., 1974) and for yeasts (Schürch et al., 1974; Wolfner et al., 1975). Starvation for a given amino acid results in simultaneous derepression not only of its own biosynthetic pathway, but also of several unrelated pathways. In $N$. crassa, starvation for either histidine, arginine or tryptophan results in a simultaneous derepression of biosynthetic enzymes for all of them. In Saccharomyces cerevisiae, the enzymes of the biosynthetic pathways for arginine, lysine, leucine, isoleucine/valine, histidine, tryptophan and probably some others are derepressed during limitation of any of these amino acids.

We have shown previously that in Aspergillus nidulans ornithine carbamoyltransferase (OCT), an enzyme of the arginine biosynthetic pathway, is derepressed under conditions of arginine limitation (Cybis et al., 1970). OCT appears to be under the control of the same regulatory gene $s u D$ as the arginine inducible enzymes of arginine catabolism (Cybis et al., 1972). The results presented here indicate the existence of a cross-pathway control of OCT synthesis.

\section{METHODS}

Strains. These were all from the collection of the Department of Genetics, University of Warsaw. The symbols arg, bi, his, lu, lys, paba, pro and pyro denote auxotrophy for arginine, biotin, histidine, leucine, lysine, $p$-aminobenzoic acid, proline and pyridoxine, respectively; $w$ and $y$ indicate white and yellow conidia, respectively.

Media. The minimal medium (MM) of Cove (1966) was used.

Methods of culture, harvesting of mycelia and preparation of extracts. These were as described previously (Cybis et al., 1970). Starvation experiments were performed in three ways. (a) About 20 h-old mycelium grown on medium with all the required supplements was collected, washed with MM, transferred to medium without amino acid supplements and harvested after $8 \mathrm{~h}$. (b) An amino acid-requiring non-leaky auxotroph was cultured on the appropriate amino acid at a growth-rate limiting concentration. The growth with the amino acid at different concentrations had previously been established by following the increase in mycelial dry weight. (c) The leaky auxotroph was grown on medium without amino acid supplements.

Enzyme assay. Ornithine carbamoyltransferase (OCT; carbamoylphosphate:L-ornithine carbamoyltransferase; EC 2.1.3.3) activity was determined as described previously (Cybis et al., 1970). 
Table 1. Effect of amino acid starvation on OCT activity

\begin{tabular}{|c|c|c|c|}
\hline Strain & Amino acid added to medium & Expt*:time (h) & $\begin{array}{c}\text { OCT activity } \\
{[\mu \text { mol citrulline }} \\
\min ^{-1} \\
\left.(\mathrm{mg} \text { protein })^{-1}\right]\end{array}$ \\
\hline biAl pabaA9 & None & - & $0 \cdot 20$ \\
\hline biAl $\arg A 1$ & None & $a: 8$ & $1 \cdot 40$ \\
\hline biAl lysB5 & None & $a: 8$ & $0 \cdot 23$ \\
\hline biAl lysB5 & Lysine (0.1 mM) & $b: 24$ & 0.45 \\
\hline biA1 lys -231 & None & $a: 8$ & $0 \cdot 25$ \\
\hline biAl luAl & None & $a: 8$ & $0 \cdot 30$ \\
\hline biAI luAI & Leucine $(0 \cdot 1 \mathrm{~mm})$ & $b: 36$ & $0 \cdot 36$ \\
\hline biAl pyro $A 4$ w-3 his-1 & None & $c: 24$ & $0 \cdot 70-1 \cdot 3$ \\
\hline biAl phen $A 2$ & None & $a: 8$ & $0 \cdot 27$ \\
\hline biAl phenA2 & Phenylalanine (0.05 mM) & $b: 24$ & $0 \cdot 36$ \\
\hline proA6 pabaA 9 biAl & None & $a: 8$ & $1 \cdot 40$ \\
\hline proA6 pabaA9 biAl & Proline $(0.2 \mathrm{~mm})$ & $b: 24$ & $0 \cdot 80-1 \cdot 5$ \\
\hline pabaA9 yA2 tryp $B 403$ & None & $a: 8$ & $1 \cdot 30$ \\
\hline pabaA9 y $A 2$ tryp $B 403$ & Tryptophan (0.05 mM) & $b: 30$ & $1 \cdot 30$ \\
\hline
\end{tabular}

Estimation of arginine pool. Extraction was performed in a boiling water bath ( $5 \mathrm{~min}$ ). Insoluble material was removed by filtration and arginine in the extract was determined by the method of Van Pilsum et al. (1956).

Chemicals. All chemicals used were of reagent grade from commercial sources, with the exception of carbamoylphosphate which was synthesized according to the method of Spector et al. (1957).

\section{RESULTS}

The OCT activity observed in the wild-type strain grown on MM represents a state of full repression of this enzyme. It cannot be repressed further by the addition of arginine. Arginine starvation results in derepression of OCT. A maximum sevenfold increase in enzyme activity took place within about $9 \mathrm{~h}$ after transferring mycelium of the arginine auxotroph $\arg A 1$ to arginine-free medium (see Cybis et al., 1970).

Mutant his- 1 is a leaky auxotroph. When grown on medium without histidine, its OCT activity increased reaching a maximum in about $24 \mathrm{~h}$. The maximum activity obtained varied from one experiment to another, but was lower than the maximum reached in the arginine-starved $\arg A 1$ strain. The presence of histidine but not arginine prevented this derepression (Tables 1 and 3 ).

3-Amino-1,2,4-triazole, a histidine analogue, inhibits histidine biosynthesis, causing a shortage of histidine a few hours after it is added to the medium of $N$. crassa (Carsiotis et al., 1974). The addition of $10 \mathrm{~mm}$-3-aminotriazole for 2.5 to $3 \mathrm{~h}$ to the growth medium of $A$. nidulans (prototrophic with regard to amino acids) resulted in a marked increase in OCT activity. This effect could be reversed by simultaneous addition of $10 \mathrm{~mm}$-histidine, but not by arginine, even at $50 \mathrm{~mm}$ (Table 2).

Tryptophan starvation of the trypB403 mutant and proline starvation of the proA6 mutant both resulted in similar high OCT activities, regardless of the starvation technique used (Table 1). For the proA6 mutant, limitation of proline at a concentration which caused only a slight decrease in the mycelium weight was sufficient to enhance OCT activity. In all other mutants tested, much more drastic changes in the growth rate were necessary for the derepression to occur.

Lysine starvation of mutants $l y s B 5, l y s D 7$ and $l y s-231$, leucine starvation of $l u A I$ and phenylalanine starvation of phenA2 mutants had little or no effect on their OCT activity. Slight derepression of OCT was sometimes observed with growth rate-limiting concentra- 
Table 2. Effect of 3-aminotriazole on the OCT activity of the pabaA9 biA1 strain

The supplements indicated were added simultaneously to a $20 \mathrm{~h}$ culture, and mycelium was harvested $3 \mathrm{~h}$ later.

\begin{tabular}{cccc} 
3-Aminotriazole & Histidine & Arginine & $\begin{array}{c}\text { OCT activity } \\
{[\mu \text { mol citrulline }} \\
\left.\min ^{-1}\left(\mathrm{mg}_{\text {protein }}\right)^{-1}\right]\end{array}$ \\
\hline 5 & - & - & 0.20 \\
10 & - & - & 0.50 \\
50 & - & - & 0.75 \\
10 & - & - & 0.48 \\
10 & 10 & - & 0.25 \\
& - & 10 & 0.77
\end{tabular}

Table 3. Effect of various amino acids on OCT activity in starved mycelium

\begin{tabular}{|c|c|c|c|}
\hline Strain & $\begin{array}{l}\text { Starvation } \\
\text { conditions }\end{array}$ & $\begin{array}{c}\text { Amino acid } \\
\text { supplementation } \\
(5 \mathrm{~mm})\end{array}$ & $\begin{array}{c}\text { OCT activity } \\
{[\mu \mathrm{mol} \text { citrulline }} \\
\left.\min ^{-1}\left(\mathrm{mg}^{2} \text { protein }\right)^{-1}\right]\end{array}$ \\
\hline biAl pyro $A 4$ w-3 his-1 & $\begin{array}{l}\text { MM } \\
24 \mathrm{~h}\end{array}$ & $\begin{array}{l}\text { Arginine } \\
\text { Ornithine } \\
\text { Proline } \\
\text { Histidine }\end{array}$ & $\begin{array}{l}0 \cdot 65 \\
0 \cdot 90 \\
0 \cdot 80 \\
0 \cdot 25\end{array}$ \\
\hline proA6 pabaA9 biA1 & $\begin{array}{l}\text { Proline }(0 \cdot 2 \mathrm{~mm}) \\
24 \mathrm{~h}\end{array}$ & $\begin{array}{l}\text { None } \\
\text { Proline }(10 \mathrm{~mm}) \\
\text { Arginine } \\
\text { Ornithine } \\
\text { Lysine } \\
\text { Glutamate } \\
\text { Alanine } \\
\text { Leucine } \\
\text { Tryptophan }\end{array}$ & $\begin{array}{l}1 \cdot 1(0 \cdot 8-1 \cdot 5) \\
0 \cdot 20 \\
0 \cdot 21 \\
0 \cdot 24 \\
0 \cdot 58 \\
0 \cdot 92 \\
1 \cdot 2 \\
1 \cdot 0 \\
1 \cdot 0\end{array}$ \\
\hline proA6 biAl agaA65 & $\begin{array}{l}\text { Proline }(0 \cdot 2 \mathrm{~mm}) \\
24 \mathrm{~h}\end{array}$ & $\begin{array}{l}\text { None } \\
\text { Arginine } \\
\text { Ornithine }\end{array}$ & $\begin{array}{l}1 \cdot 2 \\
0 \cdot 75 \\
0 \cdot 25\end{array}$ \\
\hline proA6 biA1 ap-2 & $\begin{array}{l}\text { Proline }(0.2 \mathrm{~mm}) \\
24 \mathrm{~h}\end{array}$ & $\begin{array}{l}\text { None } \\
\text { Arginine } \\
\text { Ornithine }\end{array}$ & $\begin{array}{l}1 \cdot 2 \\
1 \cdot 5 \\
1 \cdot 4\end{array}$ \\
\hline
\end{tabular}

tions of these amino acids, but no derepression occurred under conditions of complete starvation (Table 1).

The effect of addition of several amino acids on the OCT activity under conditions of amino acid deprivation is shown in Table 3. Tryptophan- or histidine-mediated derepression of OCT could not be reversed by arginine, even at high concentrations, or by any of the other amino acids tested. Repression was obtained only with the limiting amino acid.

Under proline limitation, arginine and ornithine maintained the normal repressed level of OCT. The results obtained could be attributed to the fact that the proA6 mutant can use these two amino acids as good proline sources, via arginine catabolism (Weglenski, 1966), and so there may be no proline shortage. Indeed, growth of the proA6 mutant on $0.2 \mathrm{~mm}$-proline plus $10 \mathrm{~mm}$-arginine (measured as mycelial mass obtained from equal inocula) was the same as on $10 \mathrm{~mm}$-proline. The double mutant proA6 agaA65, which lacks arginase (Bartnik et al., 1977), is unable to use arginine, but can still use ornithine as a proline source. With this strain, arginine did not support growth on 0.2 mM-proline and OCT was derepressed (Table 3). Neither arginine nor ornithine supported growth of a strain carrying, in addition to proA6, the mutation ap- 2 affecting basic amino acids transport (unpublished) and they did not cause repression of OCT in this strain (Table 3). 
Table 4. Pools of arginine under different growth conditions

\begin{tabular}{|c|c|c|}
\hline \multicolumn{3}{|c|}{$\begin{array}{l}\text { Cultures were grown for } 20 \mathrm{~h} \text { and then samples were withdrawn for extraction, except } \mathrm{f} \\
\text { experiment }(b) \text { in which a culture grown initially on } 10 \mathrm{~mm} \text {-proline was transferred to mediu } \\
\text { without proline for } 8 \mathrm{~h} \text {. }\end{array}$} \\
\hline . & $\begin{array}{l}\text { Amino acid } \\
\text { supplementation }\end{array}$ & $\begin{array}{l}\text { Arginine } \\
{\left[\mathrm{nmol}(\mathrm{mg} \text { dry } \mathrm{wt})^{-1}\right]}\end{array}$ \\
\hline pabaA9 biAl & None & 8 \\
\hline proA6 pabaA9 biAl & $\begin{array}{l}\text { Proline }(10 \mathrm{~mm}) \\
\text { Proline }(0 \cdot 2 \mathrm{~mm}) \\
\text { None }(8 \mathrm{~h}, \operatorname{expt} b)\end{array}$ & $\begin{array}{l}10 \\
95 \\
62\end{array}$ \\
\hline pabaA9 yA2 tryp B403 & $\begin{array}{l}\text { Tryptophan }(5 \mathrm{~mm}) \\
\text { Tryptophan }(0.05 \mathrm{~mm}) \\
\text { Tryptophan }(0.05 \mathrm{~mm}) \\
\quad+\text { arginine }(5 \mathrm{~mm})\end{array}$ & $\begin{array}{l}15 \\
75\end{array}$ \\
\hline
\end{tabular}

The presence in the growth medium of 3-aminotriazole during starvation for proline or tryptophan did not cause any further increase in the OCT activity.

Assay of the arginine pool under different growth conditions showed that the total pool of free arginine present in proline- or tryptophan-starved cells was very high - about as high as the maximum found in mycelium grown in the presence of $5 \mathrm{~mm}$-arginine (Table 4).

It was possible that the observed increase in OCT activity was not actually a derepression of OCT synthesis but a change in its activity. However, in a starvation experiment with the proA6 mutant in medium without amino acid supplements but containing cycloheximide at $10 \mu \mathrm{g} \mathrm{ml}^{-1}$, there was no change in OCT activity during at least $7 \mathrm{~h}$, indicating that OCT derepression required protein synthesis.

The suD19 mutant is a pleiotropic regulatory mutant which, among other characteristics, is insensitive to arginine starvation. In an $s u D 19 \arg A 1$ strain there was no difference in OCT activity whether or not arginine was present in the medium (Cybis et al., 1972). Therefore, it was interesting to see whether cross-pathway regulation operated in this mutant. 3-Aminotriazole was used to produce a shortage of histidine. The results are obscured by the fact that the OCT level in suD19 is higher than in the wild-type and increases with the age of the mycelium. Addition of $10 \mathrm{~mm}-3$-aminotriazole to exponentially growing mycelium of $s u D 19$ for 2.5 to $3 \mathrm{~h}$ resulted in an OCT specific activity of $0 \cdot 80$, compared with $0 \cdot 50$ in the absence of the analogue.

\section{DISCUSSION}

The results presented show that OCT is derepressed not only under conditions of arginine starvation but also under histidine, proline or tryptophan starvation. Little or no effect was obtained with lysine, leucine or phenylalanine deprivation. It is possible that the spectrum of amino acids participating in this phenomenon is different in different organisms, since, for example, in yeasts deprivation of practically any amino acid produces a general derepression effect.

Simultaneous starvation for different amino acids did not result in enhanced derepression, as may be concluded from the results of combined proline-histidine and tryptophanhistidine starvation (obtained with the use of the histidine analogue). The basic rule of general cross-pathway regulation is that derepression of enzymes caused by shortage of a given amino acid may be reversed only by the same amino acid. The character of OCT derepression described here fits this pattern. The results obtained with arginine and ornithine for proline-starved cells can be explained by the role of these amino acids as proline precursors. The behaviour of the proA6 agaA65 and proA6 ap-2 strains supports this conclusion. The repression is brought about by the limiting amino acid, regardless of the intracellular arginine content (see Table 4). 
Two levels of OCT regulation, general and specific, have been demonstrated in yeasts (Delforge et al., 1975). Only an approximately twofold increase in OCT activity is obtained by means of the cross-pathway regulation in the wild-type; maximum levels - about 50times higher - are reached when the mutant $\arg R$, relieved from specific repression, is the subject of non-specific amino acid starvation. The same is observed in the starved arginine auxotroph. In $A$. nidulans there was no pronounced difference in OCT activity between arginine-, proline- and tryptophan-starved cells. The activities varied from one starvation experiment to another but were all within the same range. This could be interpreted as indicating that derepression in the $\arg A l$ mutant is not the arginine-specific response, but is brought about by the cross-pathway regulation mechanism. On the other hand, the increase in OCT activity produced by 3-aminotriazole in the mutant suD19 indicates that two independently acting regulatory systems are involved.

I wish to thank Dr E. Bartnik for participation in some of the experiments. This work was supported by the Polish Academy of Sciences within the project 09.7.2.

\section{REFERENCES}

Bartnik, E., Guzewska, J., Klimczuk, J., PiotrowSKA, M. \& WEGLENSKI, P. (1977). Regulation of arginine catabolism in Aspergillus nidulans. In Genetics and Physiology of Aspergillus, pp. 243254. Edited by J. E. Smith \& J. A. Pateman. London: Academic Press.

Carsiotis, M., Jones, R. F. \& Wesseling, A. C. (1974). Cross-pathway regulation: histidinemediated control of histidine, tryptophan and arginine biosynthetic enzymes in Neurospora crassa. Journal of Bacteriology 119, 893-898.

Cove, D. J. (1966). The induction and repression of nitrate reductase in the fungus Aspergillus nidulans. Biochimica et biophysica acta 113, 51-56.

Cybis, J., Piotrowska, M. \& Weglenski, P. (1970). Control of ornithine transcarbamylase formation in Aspergillus nidulans. Bulletin de l'Académie polonaise des sciences, Sèrie des Sciences biologiques 18, 669-672.

Cybis, J., Plotrowska, M. \& Weglenski, P. (1972). Genetic control of the arginine pathways in Aspergillus nidulans. Common regulation of anabolism and catabolism. Molecular and General Genetics 118, 273-277.
Delforge, J., Messenguy, F. \& Wiame, J. M. (1975). The regulation of arginine biosynthesis in Saccharomyces cerevisiae. The specificity of $\arg R^{-}$mutations and the general control of amino acid biosynthesis. European Journal of Biochemistry 57, 231-239.

Schürch, A., Miozzari, J. \& HÜtter, R. (1974). Regulation of tryptophan biosynthesis in Saccharomyces cerevisiae: mode of action of 5methyl-tryptophan and 5-methyl-tryptophan-sensitive mutants. Journal of Bacteriology 117, 11311140.

SPector, L., Jones, M. E. \& LipmanN, F. (1957). Carbamyl phosphate. Methods in Enzymology 3, 643-655.

Van Pilsum, J. F., Martin, R. P., Kito, E. \& Hess, J. (1956). Determination of creatine, creatinine, arginine, guanidoacetic acid, guanidine and methylguanidine in biological fluids. Journal of Biological Chemistry 222, 225-236.

Wolfner, M., YeP, D., Messenguy, F. \& Fink, G. R. (1975). Integration of aminoacid biosynthesis into the cell cycle of Saccharomyces cerevisiae. Journal of Molecular Biology 90, 273-290. 